\title{
Allogeneic stem cell transplantation for AML patients with RUNX1 mutation in first complete remission: a study on behalf of the acute leukemia working party of the EBMT
}

\author{
Johanna Waidhauser $\mathbb{D}^{1} \cdot$ Myriam Labopin $\mathbb{1}^{2,3} \cdot$ Jordi Esteve $\mathbb{C}^{4} \cdot{\text { Nicolaus } \mathrm{Kröger}^{5} \cdot \text { Jan Cornelissen }}^{6}$. \\ Tobias Gedde-Dahl ${ }^{7} \cdot$ Gwendolyn Van Gorkom $^{8} \cdot$ Jürgen Finke $^{9} \cdot$ Montserrat Rovira $^{4} \cdot$ Nicolaas Schaap $^{10}$.

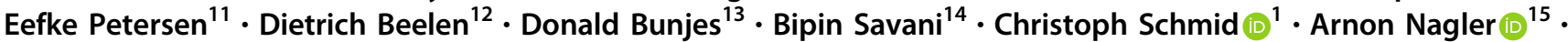 \\ Mohamad Mohty $\mathbb{B D}^{2,3,16} \cdot$ on behalf of the Acute Leukemia Working Party of EBMT
}

Received: 23 February 2021 / Revised: 9 April 2021 / Accepted: 20 April 2021 / Published online: 31 May 2021

(c) The Author(s) 2021. This article is published with open access

\begin{abstract}
Acute myeloid leukemia with runt-related transcription factor 1 gene mutation (RUNX1+ AML) is associated with inferior response rates and outcome after conventional chemotherapy. We performed a retrospective, registry-based analysis to elucidate the prognostic value of RUNX1 mutation after allogeneic stem cell transplantation (alloSCT). All consecutive adults undergoing alloSCT for AML in first complete remission (CR1) between 2013 and 2019 with complete information on conventional cytogenetics and RUNX1 mutational status were included. Endpoints of interest were cumulative relapse incidence, non-relapse mortality, overall and leukemia-free survival (OS/LFS), and GvHD-free/relapse-free survival. A total of 674 patients $(183 R U N X 1+, 491 R U N X 1-)$ were identified, with $>85 \%$ presenting as de novo AML. Median follow-up was $16.4(R U N X 1+)$ and 21.9 (RUNX1-) months. Survival rates showed no difference between $R U N X 1+$ and $R U N X 1-$ patients either in univariate or multivariate analysis (2-year OS: 67.7 vs. $66.1 \%, p=0.7 ; 2$-year LFS: 61.1 vs. $60.8 \%, p=$ 0.62). Multivariate analysis identified age, donor type and poor cytogenetics as risk factors for inferior outcome. Among patients with $R U N X+$ AML, older age, reduced intensity conditioning and minimal residual disease at alloSCT predicted inferior outcome. Our data provide evidence that the negative influence of RUNX1 mutations in patients with AML can be overcome by transplantation in CR1.
\end{abstract}

\footnotetext{
Supplementary information The online version contains supplementary material available at https://doi.org/10.1038/s41409021-01322-w.

Christoph Schmid

Christoph.schmid@uk-augsburg.de

1 Department of Hematology and Medical Oncology, University Medical Center Augsburg, Augsburg, Germany

2 EBMT Paris Study Office, Saint Antoine Hospital, Paris, France

3 INSERM UMR 938, Sorbonne University, Paris, France

4 Institute of Hematology and Oncology, Hospital Clinic Barcelona, Barcelona, Spain

5 Bone Marrow Transplantation Centre, University Hospital Eppendorf, Hamburg, Germany

6 Department of Hematology, University Medical Center Rotterdam, Rotterdam, The Netherlands

7 Clinic for Cancer Medicine, Oslo University Hospital, Rikshospitalet, Oslo, Norway

8 Department of Internal Med. Hematology /Oncology, University
}

Hospital Maastricht, Maastricht, The Netherlands

9 Department of Hematology and Medical Oncology, University of Freiburg, Freiburg, Germany

10 Department of Hematology, Nijmegen Medical Centre, Nijmegen, The Netherlands

11 Department of Hematology, University Medical Centre Utrecht, Utrecht, The Netherlands

12 Department of Bone Marrow Transplantation, University Hospital Essen, Essen, Germany

13 Klinik fuer Innere Medizin III, University Hospital Ulm, Ulm, Germany

14 Vanderbilt University Medical Center, Nashville, TN, USA

15 Tel Aviv University, BMT and Cord Blood Bank, Chaim Sheba Medical Center, Tel-Hashomer, Israel

16 Department of Hematology, Saint Antoine Hospital, Paris, France 


\section{Introduction}

Increasing knowledge about the impact of runt-related transcription factor 1 (RUNXI) gene mutation on characteristics and outcome of patients with de novo acute myeloid leukemia (AML) has led to its establishment as a provisional entity in the 2016 WHO classification [1]. In contrast to diseases with cytogenetic alterations leading to $R U N X$ transcription factor family rearrangement such as $\mathrm{t}(8 ; 21)(\mathrm{q} 22 ; \mathrm{q} 22)$, AML with RUNX1 gene mutations is associated with poorer response to conventional chemotherapy, lower rates of complete remission (CR), relapse free survival (RFS), and overall survival (OS) [2-8]. These findings led to the allocation of RUNX1 mutated AML to the adverse risk category of the 2017 European Leukemia Net (ELN) risk stratification [9]. However, data on the relevance of this mutation to the indication for and outcome after allogeneic stem cell transplantation (alloSCT) are scarce and contradictory and came mainly from subgroup analyses containing low numbers of transplant recipients. Schnittger et al. did not observe any survival advantage after alloSCT among 17 out of $97 R U N X 1+$ patients who underwent alloSCT in first CR or as salvage therapy [4]. In contrast Gaidzik et al. found a better RFS after transplantation in subgroup analyses of two different studies on $R U N X 1+$ patients, including $14 / 53$ and $36 / 245$ patients undergoing alloSCT, but without an impact of the mutation on survival among allografted patients $[5,7]$.

Here, we present the results of a large retrospective study on 674 patients, performed by the Acute Leukemia Working Party (ALWP) of the European Society for Blood and Marrow Transplantation (EBMT) and designed specifically to analyze the prognostic value of $R U N X 1$ mutation after allo SCT for AML.

\section{Methods}

\section{Patients}

Data were extracted from the EBMT registry. The EBMT is a non-profit, scientific society representing more than 600 transplant centers, that are required to report all consecutive stem cell transplantations including annual follow-up. Data are managed in a central database with internet access, annual audits are performed to verify data accuracy. Patients provide informed consent authorizing the use of their personal information for research purposes before transplantation.

This study was approved by the by the general assembly of the ALWP of the EBMT. We screened the EBMT database for adult AML patients with complete information on cytogenetics and RUNX1 mutational status, excluding patients with translocation $\mathrm{t}(8 ; 21) / R U N X 1-R U N X 1 T 1$. Further inclusion criteria were an alloSCT in CR1 between January 2013 and June 2019 from either a matched sibling donor (MSD), matched unrelated donor (MUD, with a minimum of 9/10 HLA match) or haploidentical donor (T-cell replete haplo-SCT only). Intensity of conditioning therapy (myeloablative conditioning; MAC vs. reduced-intensity conditioning; RIC), cytomegalovirus (CMV) status, T-cell depletion of transplant, and Karnofsky Perfomance Score (KPS), data on co-mutations such as nucleophosmin 1 (NPMI), FMS-like tyrosine kinase 3 internal tandem duplication (FLT3-ITD) and additional sex combs-like 1 (ASXL1) were retrieved from the registry when available, as was minimal residual disease (MRD) status at time of alloSCT (evaluated according to local standards). Outcome variables were OS and leukemia-free survival (LFS), graft-versus-host disease GvHD-free/relapse-free survival (GRFS), cumulative relapse incidence (RI), non-relapse mortality (NRM) and GvHD.

\section{Definitions and statistical analysis}

OS was defined as the time interval between dates of transplantation and death from any cause, LFS as the interval between dates of transplantation and relapse, death in remission or last follow up. Cytogenetic subgroups, acute GvHD (aGvHD) and chronic GvHD (cGvHD) were classified as previously defined [10-12], the composite endpoint GRFS was defined as survival after transplantation without aGvHD grade III-IV, or cGvHD with indication for treatment, or relapse [13]. RI was defined as the period between transplantation and disease progression, NRM as death from any cause without relapse or progression of the initially diagnosed leukemia.

Patient, disease, and transplant-related characteristics of the two cohorts (RUNXI+ and RUNXI-) were compared by using the $\chi^{2}$ or Fisher's exact test for categorical variables, and the Mann-Whitney test for continuous variables. For univariate analysis, continuous variables were categorized, and the median value used as a cutpoint; the log-rank test and Gray's test were used for comparison of outcome between groups. The date of transplantation was the starting point for time-to-event analyses. Survivors were censored at last contact. Cumulative incidence was used to estimate the endpoints of NRM, RI, aGvHD and cGVHD, accommodating for competing risks. A Cox proportional-hazards model was used for multivariate regression; all factors shown to be significant at the $p<0.05$ in the univariate analysis, or those known from the literature to possibly influence outcome were included. A random effect (frailty effect) was introduced into Cox models to consider the 
heterogeneity in the effect of a characteristic or a treatment across centers. Multivariate results are expressed as a hazard ratio (HR) with a $95 \%$ confidence interval (CI). All tests were two sided. The type- 1 error rate was fixed at 0.05 for determination of factors associated with time-toevent outcomes. All analyses were performed using SPSS 24.0 (SPSS Inc, Chicago, IL, USA)) and R version 3.4.0 (R Core Team. R: a language for statistical computing. 2014. R Foundation for Statistical Computing, Vienna, Austria).

\section{Results}

\section{Patient and disease characteristics}

A total of 674 patients (183 (27\%) with and $491(73 \%)$ without RUNX1 mutation) were included. The median age was 57 (range 18-77) years, 302 (45\%) patients were female. AML was classified as de novo disease in 88 and $83 \%$ of $R U N X 1-$ and $R U N X 1+$ patients, respectively. Most patient, disease, and transplant characteristics were equally distributed between the two cohorts, including MRD status before SCT (Table 1). However, as expected [3, 6, 14, 15], an imbalance in the frequency of NPM1 and ASXL1 mutations was observed. Thus, NPM1 mutation was detected in $26 \%$ of $R U N X 1-$ patients but in only $5 \%$ of $R U N X 1+$ patients $(p<0.0001)$. In contrast, an ASLX1 mutation was more frequent in $R U N X 1+$ patients than in those lacking this mutation (55 vs. $16 \%, p<0.0001)$. FLT3-ITD was observed at a similar frequency (26 vs. $30 \%$ ) in both groups.

\section{Overall outcome and univariate analysis}

Median follow up from SCT was 19.6\% (21.9 months among RUNX-, 16.4 months among RUNX+ patients, $p=$ 0.004). Within the entire cohort, cumulative RI and NRM were $23.8 \%$ (95\% CI: $20.2-27.6$ ) and $15.2 \%$ (95\% CI: 12.4-18.4), OS, LFS, and GRFS, at 2 years from transplantation were $66.6 \%$ (95\% CI: 62.4-70.8), 61\% (95\% CI: 56.7-65.3), and 45.5\% (95\% CI: 41.2-49.8), respectively (Table 2). Cumulative incidence of acute GvHD (aGvHD) by day 180 was $28 \%$ (95\% CI: $24.6-31.6$ ) for grades II-IV, and $9.1 \%$ (95\% CI: 7.1-11.5) for grades III-IV. At 2 years, cumulative incidence of chronic GvHD (cGvHD) was $37.8 \%$ (95\% CI: $33.5-42.1$ ) overall and $17.4 \%$ (95\% CI: 14.1-21) for extensive cGvHD. At 2 years, 189 patients had died. AML was the most frequent cause of death, accounting for $35 \%$ of all fatalities, followed by infections (24\%) and GvHD (15\%).

In univariate analysis, risk factors for inferior OS and LFS were poor cytogenetics, older age and RIC. Cytogenetics and secondary AML (sAML) were risk factors for RI,
Table 1 Demographic and disease characteristics of total population and $R U N X 1+$ and $R U N X 1-$ subgroups.

\begin{tabular}{|c|c|c|c|c|}
\hline Variables & Total & RUNX1- & RUNX1+ & $p$ value \\
\hline Age; median (range) & $57.4(18.2-77.4)$ & $56.8(18.3-77.4)$ & $58.7(18.2-75)$ & 0.067 \\
\hline Sex & & & & 0.16 \\
\hline Male; $n(\%)$ & $372(55.2)$ & $279(56.8)$ & $93(50.8)$ & \\
\hline Female; $n(\%)$ & $302(44.8)$ & $212(43.2)$ & $90(49.2)$ & \\
\hline deNovo AML; $n(\%)$ & $584(86.6)$ & $432(88)$ & $152(83.1)$ & 0.095 \\
\hline Cytogenetics & & & & 0.62 \\
\hline Intermediate; $n(\%)$ & $510(75.7)$ & $374(76.2)$ & $136(74.3)$ & \\
\hline Poor; $n(\%)$ & $164(24.3)$ & $117(23.8)$ & 47 (25.7) & \\
\hline Donor type & & & & 0.18 \\
\hline MSD; $n(\%)$ & $169(25.1)$ & $121(24.6)$ & $48(26.2)$ & \\
\hline MUD; $n(\%)$ & $451(66.9)$ & $336(68.4)$ & $115(62.8)$ & \\
\hline Haplo; $n(\%)$ & $54(8.0)$ & $34(6.9)$ & $20(10.9)$ & \\
\hline KPS & & & & 0.93 \\
\hline$<90 ; n(\%)$ & $197(30.6)$ & $142(30.5)$ & $55(30.9)$ & \\
\hline$>90 ; n(\%)$ & 446 (69.4) & $323(69.5)$ & $123(69.1)$ & \\
\hline $\begin{array}{l}\text { CMV recipient } \\
\text { serostatus }\end{array}$ & & & & 0.57 \\
\hline Positive; $n(\%)$ & $424(63.3)$ & $305(62.6)$ & $119(65)$ & \\
\hline Negative; $n(\%)$ & $246(36.7)$ & $182(37.4)$ & $64(35)$ & \\
\hline T-cell depletion & & & & 0.09 \\
\hline Yes; $n(\%)$ & 407 (60.8) & $297(61)$ & $110(60.4)$ & \\
\hline No; $n(\%)$ & $262(39.2)$ & $190(39)$ & $72(39.6)$ & \\
\hline $\begin{array}{l}\text { Intensity of } \\
\text { conditioning }\end{array}$ & & & & 0.099 \\
\hline RIC; $n(\%)$ & 359 (53.9) & $252(52)$ & $107(59.1)$ & \\
\hline MAC; $n(\%)$ & $307(46.1)$ & $233(48)$ & $74(40.9)$ & \\
\hline NPM1 & & & & $<0.0001$ \\
\hline Positive; $n(\%)$ & $126(22.9)$ & $121(26.4)$ & $5(5.4)$ & \\
\hline Negative; $n$ (\%) & $425(77.1)$ & 338 (73.6) & 87 (94.6) & \\
\hline Missing; $n$ & 123 & 32 & 91 & \\
\hline ASXL1 & & & & $<0.0001$ \\
\hline Positive; $n(\%)$ & $67(26)$ & $30(15.7)$ & $37(55.2)$ & \\
\hline Negative; $n(\%)$ & $191(74)$ & $161(84.3)$ & $30(44.8)$ & \\
\hline Missing; $n$ & 416 & 300 & 116 & \\
\hline FLT3-ITD & & & & 0.43 \\
\hline Positive; $n(\%)$ & 149 (26.6) & $119(25.9 \%)$ & $30(29.7 \%)$ & \\
\hline Negative; $n(\%)$ & 412 (73.4) & $341(74.1 \%)$ & $71(70.3 \%)$ & \\
\hline Missing; $n$ & 113 & 32 & 91 & \\
\hline MRD at HSCT & & & & 0.13 \\
\hline Positive; $n(\%)$ & $123(40.6)$ & $90(43.5)$ & $33(34.4)$ & \\
\hline Negative; $n(\%)$ & $180(59.4)$ & 117 (56.5) & $63(65.6)$ & \\
\hline Missing; $n$ & 371 & 284 & 87 & \\
\hline $\begin{array}{l}\text { Median follow up } \\
\text { (months) }\end{array}$ & 19.6 & 21.9 & 16.4 & 0.004 \\
\hline
\end{tabular}

$\overline{M S D}$ matched sibling donor, $M U D$ matched unrelated donor, KPS Karnofsky performance score, $C M V$ cytomegalovirus, RIC reduced intensity conditioning, MAC myeloablative conditioning. Statistically significant p-values are in bold.

NRM was influenced by cytogenetics, donor type, age and conditioning, and GRFS by cytogenetics and FLT3-ITD. In contrast, presence of the RUNXI mutation did not influence any of the investigated outcomes (RI, NRM, LFS, OS, and GRFS; Supplementary Table 1 and Fig. 1). Similarly, no influence of the RUNX1 mutation on any outcome parameter could be demonstrated, when the analysis was limited to 584 patients (87\%) with de novo AML or to 510 patients (76\%) with intermediate cytogenetics (Supplementary Table 2, Supplementary Figs. 1 and 2). 


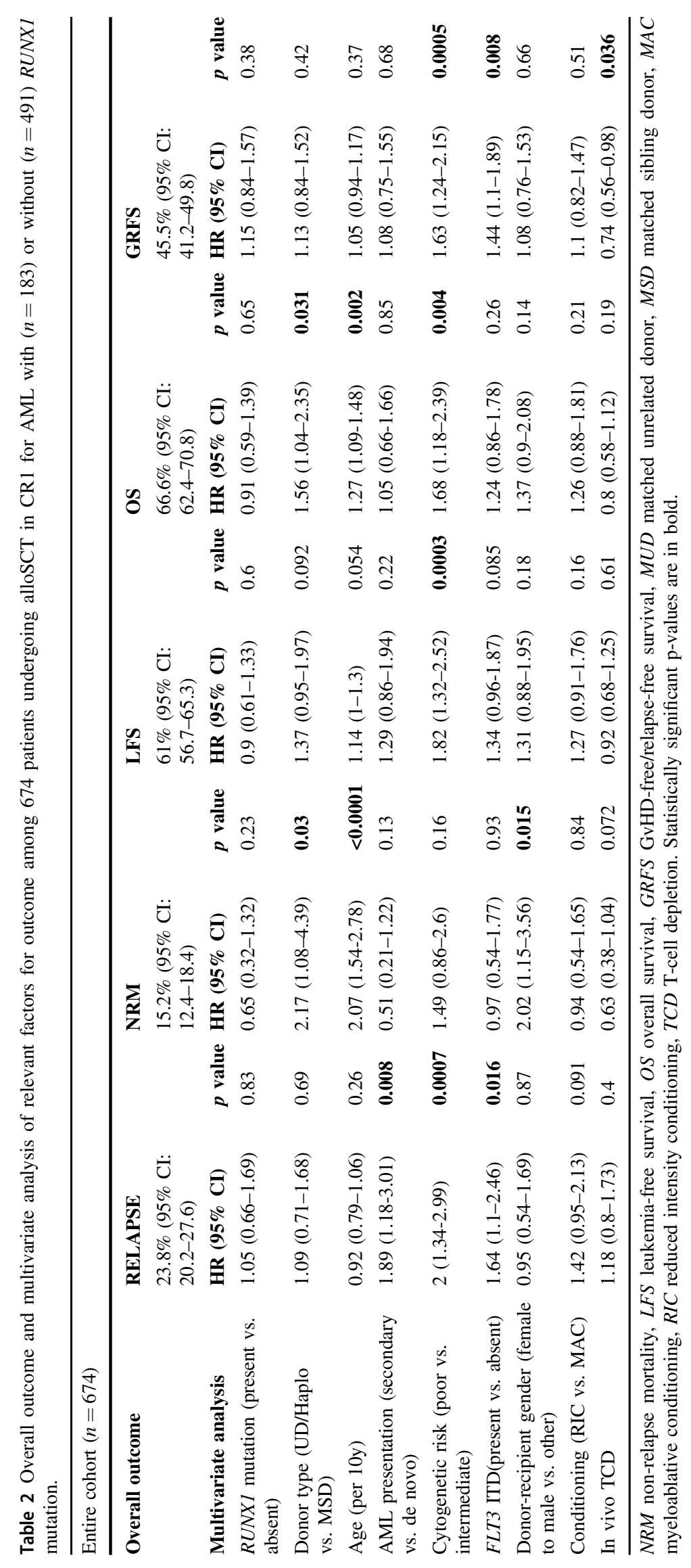



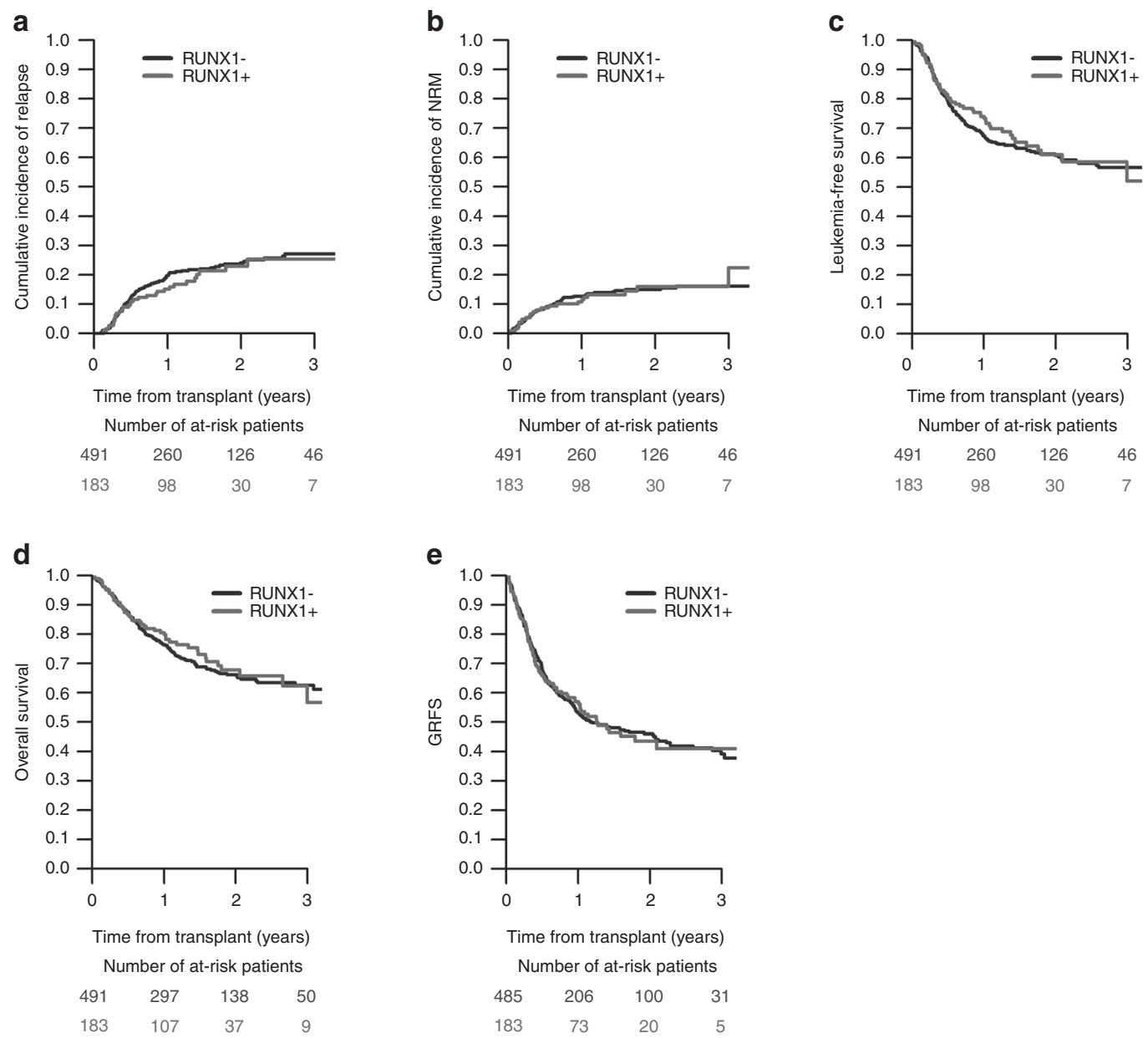

Fig. 1 Outcome of 674 patients with AML with or without RUNX1 gene mutation transplanted in first CR. a cumulative relapse incidence (RI), b non-relapse mortality (NRM), c leukemia-free survival (LFS), d overall survival (OS), e GvHD-free/relapse-free survival (GRFS).

An exploratory analysis was performed within the cohorts of patients with available data regarding ASXL1 co-mutation, since a significant interaction between these two mutations, leading to a particularly poor prognosis, had been suggested [14]. However, among 258 patients with available data on both markers (38\% of the entire cohort), the existence of both mutations was not a prognostic indicator of any outcome after allo-SCT (Supplementary Table 3).

\section{Multivariate analysis}

In a multivariate analysis of the entire cohort, sAML, poor cytogenetics, and FLT3-ITD negatively affected RI. NRM was associated with donor type other than HLA identical family donor, female donor to male patient, and older age. Donor type, older age and poor risk cytogenetics showed a negative impact on OS, poor risk cytogenetics negatively affected LFS. Factors affecting GRFS were cytogenetic category, FLT3-ITD and in vivo T-cell depletion. In contrast, RUNX1 mutational status did not show a significant influence on any outcome (Table 2). Again, similar results were obtained when the analysis was limited to patients with de novo AML. A third multivariate model was fitted for the 510 patients with intermediate cytogenetics ( $R U N X 1-, n=$ 374 , and $R U N X 1+, n=136$ ). Even in this subgroup, RUNXI mutation was not associated with any outcome, whereas older age was the main factor associated with lower OS. RI was influenced by FLT3-ITD and RIC, NRM was influenced by older age, donor type and a female donor for male recipient (Supplementary Table 4).

\section{Prognostic factors among patients bearing a RUNX1 mutation}

To further characterize this cohort, a risk factor analysis was performed among patients with AML and RUNX1 mutation. In univariate analysis, OS and LFS were influenced by cytogenetics, age (borderline significance for LFS), conditioning, MRD at time of transplantation and AML type 


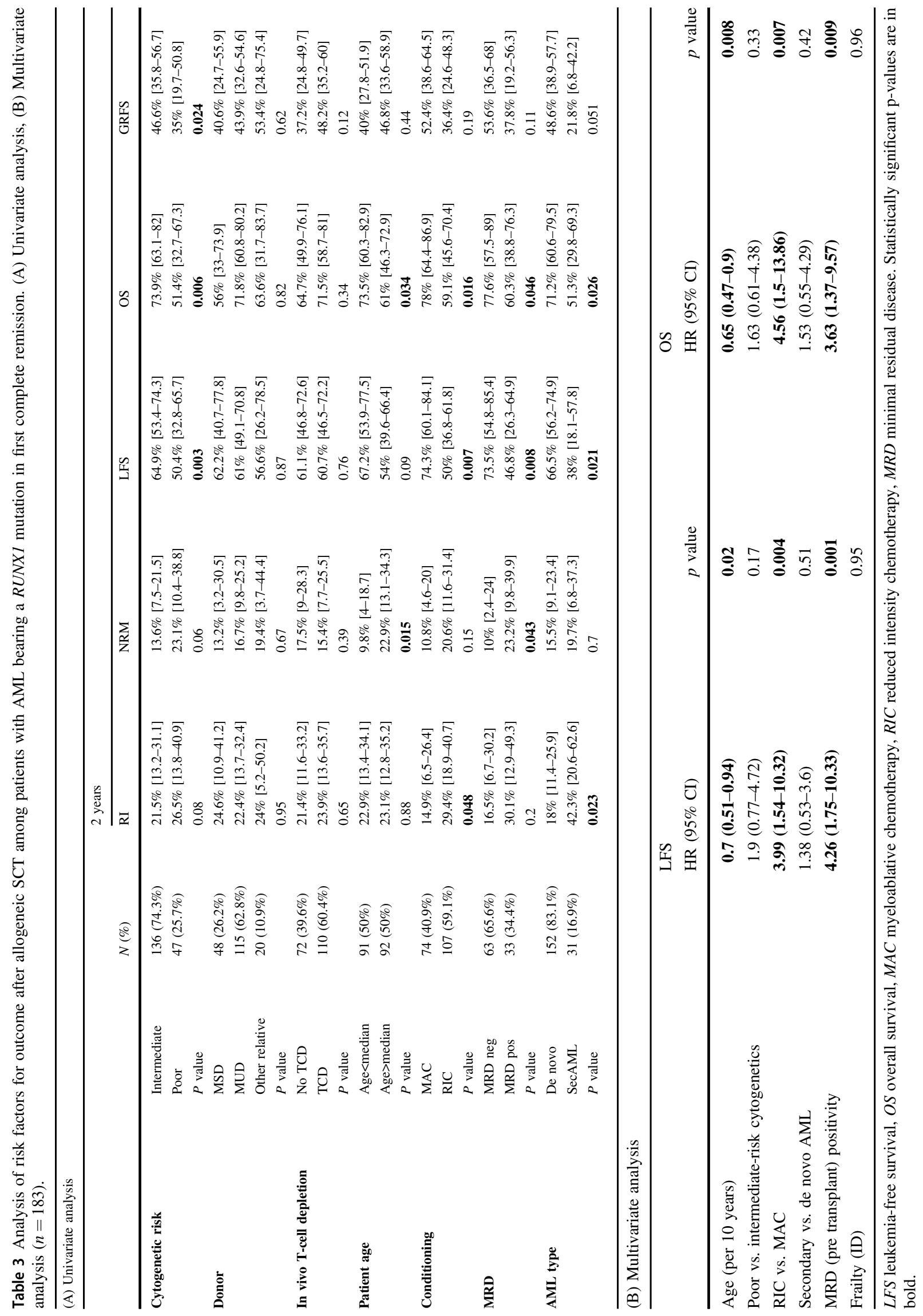


(de novo versus secondary). NRM was influenced by age and MRD status, whereas conditioning and AML subtype influenced RI. In the multivariate model, both inferior OS and LFS were significantly associated with older age, RIC, and MRD positivity. Unfortunately, the number of events was too low for a multivariate analysis of RI and NRM (Table 3).

\section{Discussion}

In the last WHO classification of myeloid malignancies, a provisional entity of AML with mutated RUNX1 was added for patients diagnosed with de novo AML containing this mutation and not harboring defining diagnostic criteria for other AML subtypes. This new provisional disease category was considered as a biologically distinct group with inferior prognosis. Moreover, most studies which have analyzed the prognostic value of RUNX1 mutation on prognosis have observed a negative impact [3-7]. Accordingly, the ELN classification has included RUNXI mutation within the adverse risk category. However, in contrast to other genetic aberrations [16, 17], information on the role of RUNXI mutation on outcome after alloSCT is scarce. Therefore, the EBMT transplant registry was used for a large-scale retrospective analysis of patients with AML and known mutational status of the RUNXI gene, who underwent alloSCT in CR1. Within this population, we did not observe a negative impact of RUNXI mutation on any outcome parameter, although follow up was shorter among RUNX+ patients. This was true within the entire cohort, and also in focused analysis among patients with de novo AML ( $>85 \%$ of the cohort), and among patients with intermediate-risk cytogenetics. The role of classical risk factors on outcome was not modified by the presence of a $R U N X 1$ mutation. Within the cohort of RUNX1+ patients, age, intensity of conditioning and MRD status before transplantation were associated with outcome after alloSCT in CR1. Hence, optimal disease control and use of myeloablative conditioning might be ways to improve outcome in this particular AML subtype.

Unlike other studies on the role of RUNXI mutation on the outcome after alloSCT, this analysis has mainly included patients with de novo AML, which all had been transplanted in CR1. In contrast to our results, an association of the RUNXI mutation with inferior outcome after allogeneic transplantation was found among patients transplanted for MDS or sAML [18]. This difference might be explained by the inclusion of both diseases, and of patients transplanted in different disease status (CR, active disease) in the latter study. However, compared to de novo disease, RUNX1 mutations might also have different clinical consequences in MDS and sAML [19, 20], as these diseases comprise higher rates of additional mutations such as ASXL1, TET2, and EZH2 [21], leading to the classification of sAML as a separate biological entity by several researchers [22]. This was supported recently by the finding that SAML is an independent risk factor for lower OS and LFS after alloSCT, as compared to de novo AML [23].

MRD status has been proven to be a strong predictor for outcome both after conventional induction therapy [24] and allogeneic transplantation [25, 26], regardless of MRD methodology and threshold [27]. Although MRD measurement techniques were heterogenous and followed local standards, this was also observed in our study, where MRD positivity at time of alloSCT was associated with inferior LFS, OS and GRFS among patients with RUNX1 mutation (Table 3). Unfortunately, missing data on MRD status in a relevant number of patients prevented the inclusion of MRD status in the multivariate model of the entire study population. However, since there was no association between MRD and RUNXI mutational status (Table 1), it is at least unlikely that differences in MRD status at time of alloSCT have introduced a bias into the comparison between $R U N X 1+$ and $R U N X I-$ cohorts.

Regarding co-mutations of RUNX1, FLT3-ITD was observed with similar frequency among RUNXI+ and $R U N X 1$ - patients, which is consistent with prior findings [4]. Whereas the previously described negative prognostic influence of FLT3-ITD [28] was reflected in our study by a higher RI and shorter GRFS, there was no mutual interaction of FLT3-ITD and RUNX1 mutation with respect to outcome. As expected, the presence of ASXL1 mutation was more frequent in $R U N X 1+$ than $R U N X 1$ - patients [14]. The coexistence of RUNXI and ASXL1 mutations has been described as a strong adverse prognostic factor in two series of AML patients [14, 29]. However, in our study, ASXL1 as single factor did not have any influence on outcome in univariate analysis, nor did the different combinations of RUNXI and ASXL1 mutational status (cf. Supplementary Table 3). This finding is in line with an extensive analysis by Schnittger et al., who could not detect a functional interaction between the two mutations [4]. Hence, our data might indicate that allogeneic transplantation could also have a positive effect on the otherwise negative prognosis in RUNX1+/ASXL1+ patients. However, since ASXL1 mutational status could not be included into the multivariate model, this observation must be interpreted with caution and warrants confirmation in a larger cohort.

In summary, this study is the largest analysis focusing specifically on the relevance of RUNXI mutational status on the outcome of allogeneic SCT performed in CR1. Since RUNX1 mutations were not associated with inferior outcome, the data might suggest that the negative influence of RUNXI mutations in patients with AML can be overcome by early transplantation. This may be especially true for $d e$ novo disease, representing $>85 \%$ of our cohort. Extensive 
molecular profiling is warranted to further investigate the interaction between different mutations and their influence on outcome after alloSCT.

\section{Data availability}

Source data are stored in the ALWP/EBMT database and can be shared upon personal request.

Author contributions JW, ML, JE, BS, CS, AN and MM designed the study, interpreted the data and wrote the manuscript, ML performed the statistical analysis, NK, JC, TG-D, GvG, JF, MR, NS, EP, DB, and DB provided patient data, contributed to the analysis and critically revised the manuscript.

Funding Open Access funding enabled and organized by Projekt DEAL.

\section{Compliance with ethical standards}

Conflict of interest The authors declare no competing interest.

Publisher's note Springer Nature remains neutral with regard to jurisdictional claims in published maps and institutional affiliations.

Open Access This article is licensed under a Creative Commons Attribution 4.0 International License, which permits use, sharing, adaptation, distribution and reproduction in any medium or format, as long as you give appropriate credit to the original author(s) and the source, provide a link to the Creative Commons license, and indicate if changes were made. The images or other third party material in this article are included in the article's Creative Commons license, unless indicated otherwise in a credit line to the material. If material is not included in the article's Creative Commons license and your intended use is not permitted by statutory regulation or exceeds the permitted use, you will need to obtain permission directly from the copyright holder. To view a copy of this license, visit http://creativecommons. org/licenses/by/4.0/.

\section{References}

1. Arber DA, Orazi A, Hasserjian R, Thiele J, Borowitz MJ, Le Beau $\mathrm{MM}$, et al. The 2016 revision to the World Health Organization classification of myeloid neoplasms and acute leukemia. Blood. 2016;127:2391-405. https://doi.org/10.1182/blood-2016-03-643544

2. Prada-Arismendy J, Arroyave JC, Rothlisberger S. Molecular biomarkers in acute myeloid leukemia. Blood Rev. 2017;31:63-76. https://doi.org/10.1016/j.blre.2016.08.005

3. Tang JL, Hou HA, Chen CY, Liu CY, Chou WC, Tseng MH, et al. AML1/RUNX1 mutations in 470 adult patients with de novo acute myeloid leukemia: prognostic implication and interaction with other gene alterations. Blood. 2009;114:5352-61. https://doi. org/10.1182/blood-2009-05-223784

4. Schnittger S, Dicker F, Kern W, Wendland N, Sundermann J, Alpermann T, et al. RUNX1 mutations are frequent in de novo AML with noncomplex karyotype and confer an unfavorable prognosis. Blood. 2011;117:2348-57. https://doi.org/10.1182/ blood-2009-11-255976

5. Gaidzik VI, Bullinger L, Schlenk RF, Zimmermann AS, Rock J, Paschka P, et al. RUNX1 mutations in acute myeloid leukemia: results from a comprehensive genetic and clinical analysis from the AML study group. J Clin Oncol : Off J Am Soc Clin Oncol. 2011;29:1364-72. https://doi.org/10.1200/jco.2010.30.7926

6. Mendler JH, Maharry K, Radmacher MD, Mrozek K, Becker H, Metzeler $\mathrm{KH}$, et al. RUNX1 mutations are associated with poor outcome in younger and older patients with cytogenetically normal acute myeloid leukemia and with distinct gene and MicroRNA expression signatures. J Clin Oncol : Off J Am Soc Clin Oncol. 2012;30:3109-18. https://doi.org/10.1200/jco.2011.40.6652

7. Gaidzik VI, Teleanu V, Papaemmanuil E, Weber D, Paschka P, Hahn J, et al. RUNX1 mutations in acute myeloid leukemia are associated with distinct clinico-pathologic and genetic features. Leukemia. 2016;30:2160-8. https://doi.org/10.1038/leu.2016.126

8. Greif PA, Konstandin NP, Metzeler KH, Herold T, Pasalic Z, Ksienzyk B, et al. RUNX1 mutations in cytogenetically normal acute myeloid leukemia are associated with a poor prognosis and upregulation of lymphoid genes. Haematologica. 2012;97:1909-15. https://doi.org/10.3324/haematol.2012.064667

9. Dohner H, Estey E, Grimwade D, Amadori S, Appelbaum FR, Buchner T, et al. Diagnosis and management of AML in adults: 2017 ELN recommendations from an international expert panel. Blood. 2017;129:424-47. https://doi.org/10.1182/blood-2016-08733196

10. Grimwade D, Walker H, Oliver F, Wheatley K, Harrison C, Harrison G, et al. The importance of diagnostic cytogenetics on outcome in AML: analysis of 1,612 patients entered into the MRC AML 10 trial. The Medical Research Council Adult and Children's Leukaemia Working Parties. Blood. 1998;92:2322-33.

11. Przepiorka D, Weisdorf D, Martin P, Klingemann HG, Beatty P, Hows J, et al. 1994 consensus conference on acute GVHD Grading. Bone Marrow Transplant 1995;15:825-8.

12. Jagasia MH, Greinix HT, Arora M, Williams KM, Wolff D, Cowen EW, et al. National Institutes of Health Consensus Development Project on Criteria for Clinical Trials in Chronic Graft-versus-Host Disease: I. The 2014 Diagnosis and Staging Working Group report. Biol Blood Marrow Transpl. 2015;21:389-401.e1. https://doi.org/10.1016/j.bbmt.2014.12.001

13. McCurdy SR, Kasamon YL, Kanakry CG, Bolaños-Meade J, Tsai HL, Showel MM, et al. Comparable composite endpoints after HLA-matched and HLA-haploidentical transplantation with posttransplantation cyclophosphamide. Haematologica. 2017;102: 391-400. https://doi.org/10.3324/haematol.2016.144139

14. Paschka P, Schlenk RF, Gaidzik VI, Herzig JK, Aulitzky T, Bullinger L, et al. ASXL1 mutations in younger adult patients with acute myeloid leukemia: a study by the German-Austrian Acute Myeloid Leukemia Study Group. Haematologica. 2015;100:324-30. https://doi.org/10.3324/haematol.2014.114157

15. Sood RKY, Liu P. Role of RUNX1 in hematological malignancies. Blood. 2018;131:373 https://doi.org/10.1182/blood2017-12-819789

16. Schmid C, Labopin M, Socié G, Daguindau E, Volin L, Huynh A, et al. Outcome of patients with distinct molecular genotypes and cytogenetically normal AML after allogeneic transplantation. Blood. 2015;126:2062-9. https://doi.org/10.1182/blood-2015-06651562

17. Poiré X, Labopin M, Maertens J, Yakoub-Agha I, Blaise D, Ifrah $\mathrm{N}$, et al. Allogeneic stem cell transplantation in adult patients with acute myeloid leukaemia and $17 \mathrm{p}$ abnormalities in first complete remission: a study from the Acute Leukemia Working Party (ALWP) of the European Society for Blood and Marrow Transplantation (EBMT). J Hematol Oncol 2017;10:20 https://doi.org/ 10.1186/s13045-017-0393-3

18. Della Porta MG, Galli A, Bacigalupo A, Zibellini S, Bernardi M, Rizzo E, et al. Clinical effects of driver somatic mutations on the outcomes of patients with myelodysplastic syndromes treated with allogeneic hematopoietic stem-cell transplantation. J Clin Oncol : 
Off J Am Soc Clin Oncol. 2016;34:3627-37. https://doi.org/10. 1200/jco.2016.67.3616

19. Stengel A, Kern W, Meggendorfer M, Haferlach T, Haferlach C. RUNX1 mutations in MDS, s-AML, and de novo AML: differences in accompanying genetic alterations and outcome. Leuk Lymphoma. 2019;60:1334-6. https://doi.org/10.1080/10428194. 2018.1522439

20. Shreve J, Nazha A. The evolving landscape of myelodysplastic syndrome prognostication. Clin Hematol Int. 2020;2:43-8. https:// doi.org/10.2991/chi.d.200408.001

21. Haferlach T, Nagata Y, Grossmann V, Okuno Y, Bacher U, Nagae $\mathrm{G}$, et al. Landscape of genetic lesions in 944 patients with myelodysplastic syndromes. Leukemia. 2014;28:241-7. https://doi. org/10.1038/leu.2013.336

22. Cheung E, Perissinotti AJ, Bixby DL, Burke PW, Pettit KM, Benitez LL, et al. The leukemia strikes back: a review of pathogenesis and treatment of secondary AML. Ann Hematol. 2019;98:541-59. https://doi.org/10.1007/s00277-019-03606-0

23. Schmaelter AK, Labopin M, Socié G, Itälä-Remes M, Blaise D, Yakoub-Agha I, et al. Inferior outcome of allogeneic stem cell transplantation for secondary acute myeloid leukemia in first complete remission as compared to de novo acute myeloid leukemia. Blood Cancer J. 2020;10:26 https://doi.org/10.1038/ s41408-020-0296-3

24. Chen X, Xie H, Wood BL, Walter RB, Pagel JM, Becker PS, et al. Relation of clinical response and minimal residual disease and their prognostic impact on outcome in acute myeloid leukemia. $\mathbf{J}$ Clin Oncol: Off J Am Soc Clin Oncol. 2015;33:1258-64. https:// doi.org/10.1200/jco.2014.58.3518
25. Walter RB, Gooley TA, Wood BL, Milano F, Fang M, Sorror ML, et al. Impact of pretransplantation minimal residual disease, as detected by multiparametric flow cytometry, on outcome of myeloablative hematopoietic cell transplantation for acute myeloid leukemia. J Clin Oncol: Off J Am Soc Clin Oncol. 2011;29:1190-7. https://doi.org/10.1200/jco.2010.31.8121

26. Gilleece MH, Labopin M, Yakoub-Agha I, Volin L, Socié G, Ljungman $\mathrm{P}$, et al. Measurable residual disease, conditioning regimen intensity, and age predict outcome of allogeneic hematopoietic cell transplantation for acute myeloid leukemia in first remission: A registry analysis of 2292 patients by the Acute Leukemia Working Party European Society of Blood and Marrow Transplantation. Am J Hematol. 2018;93:1142-52. https://doi.org/10.1002/ajh.25211

27. Nagler A, Baron F, Labopin M, Polge E, Esteve J, Bazarbachi A, et al. Measurable residual disease (MRD) testing for acute leukemia in EBMT transplant centers: a survey on behalf of the ALWP of the EBMT. Bone Marrow Transpl. 2020. https://doi. org/10.1038/s41409-020-01005-y

28. Port M, Böttcher M, Thol F, Ganser A, Schlenk R, Wasem J, et al. Prognostic significance of FLT3 internal tandem duplication, nucleophosmin 1, and CEBPA gene mutations for acute myeloid leukemia patients with normal karyotype and younger than 60 years: a systematic review and meta-analysis. Ann Hematol. 2014;93:1279-86. https://doi.org/10.1007/s00277-014-2072-6

29. Stengel A, Kern W, Meggendorfer M, Nadarajah N, Perglerovà K, Haferlach T, et al. Number of RUNX1 mutations, wild-type allele loss and additional mutations impact on prognosis in adult RUNX1-mutated AML. Leukemia. 2018;32:295-302. https://doi. org/10.1038/leu.2017.239 